\title{
Study on processing technology of modified pomelo peel on acid dye neutral red wastewater
}

\author{
Zijun Wang ${ }^{1, a}$, Xinlong Jiang ${ }^{2, b *}$ \\ ${ }^{1}$ Zhejiang Shuren University, Hangzhou, China \\ ${ }^{2}$ Institute of Food and Fermentation Engineering,Zhejiang Shuren University, Hangzhou, China \\ aemail:1060180397@qq.com, ${ }^{\text {bemail:jxinl2003@163.com }}$
}

Keywords:Modified pomelo peel; Neutral red ; Adsorption Conditions; Orthogonal experiment. Abstract: The waste pomelo peel modified and orthogonal optimization of adsorption conditions of neutral red was studied.The results showed pomelo peel modified with $0.1 \mathrm{~mol} \cdot \mathrm{L}^{-1}$ acetic acid was the best.The optimal processing conditions were as follows: $100 \mathrm{~mL}$ neutral red solution of 200 $\mathrm{mg} \cdot \mathrm{L}^{-1}$, adding $3.0 \mathrm{~g} \cdot \mathrm{L}^{-1}$ modified pomelo peel of $60 \sim 80$ mesh and adsorbed for $\mathrm{pH} 5.0,30^{\circ} \mathrm{C}, 1.0 \mathrm{~h}$. Under the optimal conditions, the maximal absorption rate got $93.15 \%$.

\section{Introduction}

With the development of acrylic manufacturing technology and increasing amount of dyeing wastewater emissions, the waster water had been the main pollution sources in China. The traditional dye wastewater treatment method including sedimentation, oxidation, flocculating, film separation and active carbon adsorption, etc [1], but these techniques had not been widely applied for the high cost or low efficiency. Biological adsorption method had been concerned for the advantages of simple operation, low cost and non-secondary pollution, etc [2-4].

Pomelo peel is a waste of agricultural processing. It is produced in large quantities yet lacks effective utilization.In this work, the waste pomelo peel has been modified through physical and chemical methods to generate suitable biosorption material. As a typical representative of cationic dye used in acrylic material, adsorption conditions of the neutral red was studied by modified pomelo peel.The effective parameters such as $\mathrm{pH}$, contact time, adsorbent quantity, adsorbent temperature, particle size, and initial concentration of adsorbate on the adsorption rate were optimized in order to maximize the removal of neutral red and provides a theoretical basis for the potential utilization of the waste pomelo peel in purifying wastewater containing low concentration neutral red .

\section{Material and Methods}

\section{Reagents and instruments}

Preparation of modified pomelo peels biosorbent: The pomelo peel was purchased from the Hangzhou farmer's market, washed with tap water and dried at $60^{\circ} \mathrm{C}$ to constant weight, then broiled in acid-base solution with different concentration for $2 \mathrm{~h}$. The resulting solid was filtered and washed with plenty of water until neutral, then dried at $50{ }^{\circ} \mathrm{C}$ to constant weight. Then the pomelo peels biosorbent were crushed using a universal grinder and sieved (60-80 mesh), and the resulting particles were stored in a desiccator until use.

Reagents:The Neutral red used in the experiment was a kind a cationic dye, with the molecular formula of $\mathrm{C}_{15} \mathrm{H}_{16} \mathrm{~N}_{4} \cdot \mathrm{HCl}$ and molecular weight of 288.8 , named "3-7-a amino amino-2-"methyl diazoxide hydrochloride", the maximal adsorption wavelength $\lambda_{\max }$ was of $530 \mathrm{~nm}$. The dye were dried at $80^{\circ} \mathrm{C}$ to a constant weight and prepared for $500 \mathrm{mg} \cdot \mathrm{L}^{-1}$ and diluted to suitable concentrations for utilization.All reagents were of analytic grade.Distilled water was used in the experiment.

Instruments:7220 spectrophotometer (Shanghai Precision Instrument Co., Ltd.),electronic balance (FA1004N), pHS-3B precision pH meter (Guangzhou Xinying Electrical Co., Ltd.), high-speed refrigerated centrifuge (GL-20G- II ), HX-200 universal grinder (Hangzhou Sansi Instruments Co., Ltd.),SHA-B water bath thermostat oscillator (Shanghai Yuejin Medical Instrument Factory). 


\section{Adsorption rate Determination}

A series of $100 \mathrm{~mL}$ neutral red dye solution were placed in $250 \mathrm{~mL}$ conical flask and adjusted the $\mathrm{pH}$ to scheduled value with $0.1 \mathrm{~mol} \cdot \mathrm{L}^{-1} \mathrm{~L} \mathrm{HCl}$ or acetic acid, then added the modified pomelo peel, the bottles were settled in constant warm water shaker and shaken for a scheduled time, then the cake and solution were separated by a filter, the solution were centrifuged at $5000 \mathrm{r} \cdot \mathrm{min}^{-1}$ to separated the particles, then the supernatant adsorption were measured at $530 \mathrm{~nm}$ with 7220 spectrometer. The concentration were calculated by a standard curve equation. The adsorption rate $(\mathrm{P})$ were calculated by the following equation: $\mathrm{P} \%=100 *\left(\mathrm{C}_{0}-\mathrm{C}_{\mathrm{e}}\right) / \mathrm{C}_{0}$

In which, the $\mathrm{C}_{0}$ was the initial dye concentration $\left(\mathrm{mg} \cdot \mathrm{L}^{-1}\right)$ and the $\mathrm{C}_{\mathrm{e}}$ was the dye concentration $\left(\mathrm{mg} \cdot \mathrm{L}^{-1}\right)$ at equivalent state.

\section{Orthogonal experiment optimization of adsorption conditions}

Because the orthogonal test design less test times, high efficiency, simple calculation and other advantages, its has been widely applied in many research fields of medical, industrial production etc[5-6].Adsorption experiment optimization including $\mathrm{pH}$ value, adsorption time, adsorbent quantity,adsorption temperature, initial concentration choice, for which several factors are parallel single factor experiment, study their influence on adsorption.

$100 \mathrm{~mL}$ of the neutral red solution were shaken at $150 \mathrm{r} \cdot \mathrm{min}^{-1}$ in $250 \mathrm{~mL}$ conical flask, single factors experiments of different particles (20-40, 40-60, 60-80, 80-100 and over 100 meshes), $\mathrm{pH}$ value $(1,2,3,4,5,6,7,8,9)$, adsorbent quantity $\left(1.0,2.0,3.0,4.0,5.0,6.0 \mathrm{~g} \cdot \mathrm{L}^{-1}\right)$, adsorption time $(0.25$, $0.5,0.75,1.0,2.0,3.0 \mathrm{~h})$, initial concentration $(50,100,150,200,300,400,500 \mathrm{mg} / \mathrm{L})$, adsorbent temperature $\left(30,35,40,45,50{ }^{\circ} \mathrm{C}\right)$ were carried out. The results showed that with the decrease of the adsorbent particles, the adsorption rate increased till the particles of 60-80 meshes, the adsorption rate reached nearly the maximal value. With the increasing of initial concentration from 50 to $500 \mathrm{mg} \cdot \mathrm{L}^{-1}$, the adsorption rate of neutral red decreased and when the original concentration of neutral red less than $200 \mathrm{mg} \cdot \mathrm{L}^{-1}$, the adsorption rate was above $95 \%$. With the increasing of adsorbent temperature from 30 to $50{ }^{\circ} \mathrm{C}$, the adsorption rate of neutral red changed little and the optimal temperature was of $30{ }^{\circ} \mathrm{C}$. The $60-80$ meshes of pomelo peel,original concentration of $200 \mathrm{mg} \cdot \mathrm{L}^{-1}$ neutral red and $30{ }^{\circ} \mathrm{C}$ adsorbent temperature were selected in the following experiments. The single factor test results were shown in Fig 1.According to Fig 1,we designed the $\mathrm{L}_{9}\left(3^{3}\right)$ program of orthogonal test in Table 1.Results were disposed by the intuitive analysis and variance analysis, significant test of neutral red adsorption factor by Duncan [5].

Table 1 Levels and factors of orthogonal experiment design

\begin{tabular}{|c|c|c|c|}
\hline Level & A $\mathrm{pH}$ value & $\mathrm{B}$ adsorption time $/ \mathrm{h}$ & $\mathrm{C}$ adsorbent quantity $/ \mathrm{g} \cdot \mathrm{L}$ \\
\hline 1 & 3 & 0.5 & 2 \\
\hline 2 & 4 & 1.0 & 3 \\
\hline 3 & 5 & 1.5 & 4 \\
\hline
\end{tabular}
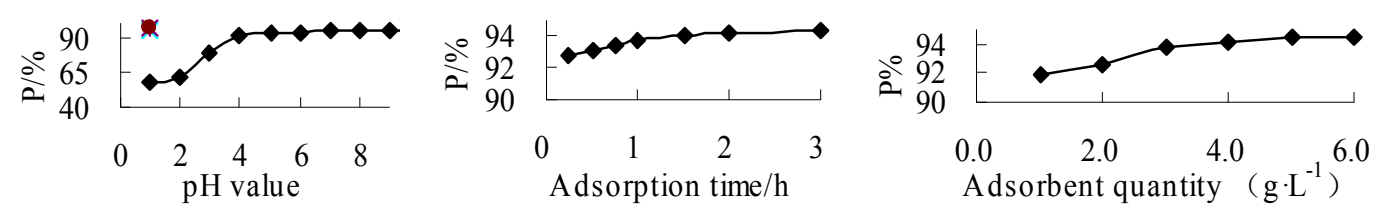

Fig.1 Effects of different factors on neutral red adsorption rate 


\section{Result and analysis}

\section{The test results of modification experiment}

Comparing modified effect under the optimal conditions:initial concentration $200 \mathrm{mg} \cdot \mathrm{L}^{-1}$, adsorbent quantity $4.0 \mathrm{~g} \cdot \mathrm{L}^{-1}$ pomelo peel of $60 \sim 80$ mesh, adsorption time $1.5 \mathrm{~h}$, extraction temperature $30^{\circ} \mathrm{C}, \mathrm{pH}$ 5.0. From Fig. 2 can be seen, modified effect with $0.1 \mathrm{~mol} \cdot \mathrm{L}^{-1}$ acetic acid was the best.

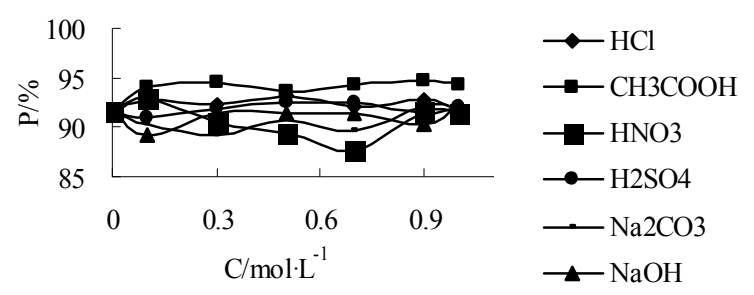

Fig.2 Comparing the modified effect

\section{The test results of orthogonal experiment}

Based on the results of single factors experiments, the adsorption experiments were carried out by orthogonal experiment design according to Table 2.

\section{The intuitive analysis}

From Table 2 can be seen, the effect of $\mathrm{pH}$ value on the rate of adsorption was the maximum. The range of data $\mathrm{R}$ was visible, the effect order of various factors on the adsorption: $\mathrm{pH}$ value>adsorption time >adsorbent quantity, the optimum adsorption conditions were: $\mathrm{A}_{3} \mathrm{~B}_{3} \mathrm{C}_{3}$, namely $\mathrm{pH}$ value was 5.0, adsorption time was $1.5 \mathrm{~h}$, adsorbent quantity was $4 \mathrm{~g} \cdot \mathrm{L}^{1}$. The result of orthogonal experiment is consistent with the single factor experiment.

Table 2 Orthogonal experimental program and results of adsorption $(n=3)$

\begin{tabular}{cccccc}
\hline No. & $\mathrm{A}$ & $\mathrm{B}$ & $\mathrm{C}$ & $\mathrm{D}$ & $\mathrm{P} / \%$ \\
\hline 1 & 1 & 1 & 1 & 1 & 61.13 \\
2 & 1 & 2 & 2 & 2 & 70.00 \\
3 & 1 & 3 & 3 & 3 & 74.78 \\
4 & 2 & 1 & 2 & 3 & 88.07 \\
5 & 2 & 2 & 3 & 1 & 91.61 \\
6 & 2 & 3 & 1 & 2 & 90.91 \\
7 & 3 & 1 & 3 & 2 & 92.80 \\
8 & 3 & 2 & 1 & 3 & 92.63 \\
9 & 3 & 3 & 2 & 1 & 93.68 \\
$\mathrm{~K}_{1}$ & 68.64 & 80.67 & 81.56 & 82.14 & \\
$\mathrm{~K}_{2}$ & 90.20 & 84.75 & 83.92 & 84.57 & \\
$\mathrm{~K}_{3}$ & 93.04 & 86.46 & 86.40 & 85.16 & \\
$\mathrm{R}$ & 24.40 & 5.79 & 4.84 & 3.02 & \\
\hline
\end{tabular}

\section{The analysis of variance}

We can see from Table 3,pH value was significant influencing factor, the other factor is not significant factor.Its could consider to determine, as determined by the Duncan method after checking back. 
Table 3 Analysis of variance

\begin{tabular}{cccccc}
\hline source of variation & SS & df & MS & F & significance \\
\hline A & 1068.2592 & 2 & 534.1296 & 69.4875 & $*$ \\
B & 53.0946 & 2 & 26.5473 & 3.4537 & \\
C & 35.1456 & 2 & 17.5728 & 2.2861 & \\
D & 15.3734 & 2 & 7.6867 & 1.0000 & \\
SS $_{\mathrm{T}}$ & 1171.8728 & 8 & & & \\
\hline
\end{tabular}

Note: $\mathrm{F}_{0.05}(2 、 2)=19.00$; “*”represents a significant influencing factors.

\section{The Duncan analysis [5]}

First were found between the level of various factors $r_{0.05}, r_{0.05}\left(r_{0.05}=6.09, r_{0.01}=14\right)$, then calculate the value of $\mathrm{R}_{\mathrm{k}}$ (standard error is 0.657 , the $\mathrm{R}_{\mathrm{k}}=$ standard error ${ }^{*} \mathrm{r}$ ). According to the calculation results, it was compared for each factor level significantly.From Table 4 can be seen, every factors had significant differences. The adsorption quantity was significantly at $3.0 \mathrm{~g} \cdot \mathrm{L}^{-1}$ and $5.0 \mathrm{~g} \cdot \mathrm{L}^{-1}$ only, the $\mathrm{pH}$ value of 3.0 and the adsorbent time $0.5 \mathrm{~h}$ were significantly to the other, respective. Considering the use of energy and resources, comprehensive analysis to determine the optimal adsorption conditions of neutral red was $\mathrm{A}_{3} \mathrm{~B}_{2} \mathrm{C}_{2}$.

Table 4. Comparison of significant difference in four levels of factors

\begin{tabular}{cccccccccccc}
\hline \multicolumn{3}{c}{$1(\mathrm{~A})$} & \multicolumn{1}{c}{$2(\mathrm{~B})$} & \multicolumn{1}{c}{$3(\mathrm{C})$} \\
\hline Level & $\mathrm{Y}$ & $\mathrm{P}_{0.05}$ & $\mathrm{P}_{0.01}$ & Level & $\mathrm{Y}$ & $\mathrm{P}_{0.05}$ & $\mathrm{P}_{0.01}$ & Level & $\mathrm{Y}$ & $\mathrm{P}_{0.05}$ & $\mathrm{P}_{0.01}$ \\
3 & 93.04 & $\mathrm{a}$ & $\mathrm{A}$ & 3 & 86.46 & $\mathrm{a}$ & $\mathrm{A}$ & 3 & 86.40 & $\mathrm{a}$ & $\mathrm{A}$ \\
2 & 90.20 & $\mathrm{a}$ & $\mathrm{A}$ & 2 & 84.75 & $\mathrm{a}$ & $\mathrm{A}$ & 2 & 83.92 & $\mathrm{ab}$ & $\mathrm{A}$ \\
1 & 68.64 & $\mathrm{~b}$ & $\mathrm{~B}$ & 1 & 80.67 & $\mathrm{~b}$ & $\mathrm{~A}$ & 1 & 81.56 & $\mathrm{~b}$ & $\mathrm{~A}$ \\
\hline
\end{tabular}

\section{The optimal process validation}

Under the optimal adsorption conditions, repeated for 3 times, the adsorption rate were: $93.24 \%, 93.06 \%, 93.15 \%$, the average of adsorption rate was $93.15 \%, \mathrm{RSD}=1.78 \%(\mathrm{n}=3)$. It was the same basically to result of orthogonal experiment.

\section{Conclusion}

The waste pomelo peel modified with $0.1 \mathrm{~mol} \cdot \mathrm{L}^{1}$ acetic acid was the best.The results of orthogonal experiment showed that the $\mathrm{pH}$ value was significant influencing factor on neutral red adsorption rate. The optimal processing conditions were as follows: $\mathrm{pH}$ value 5.0, adsorbent quantity 3.0 $\mathrm{g} \cdot \mathrm{L}^{-1}$, adsorption time $1.0 \mathrm{~h}$, adsorbent temperature $30{ }^{\circ} \mathrm{C}$, initial concentration of $200 \mathrm{mg} \cdot \mathrm{L}^{1}$, the particles of $60-80$ meshes, shaker rotation of $150 \mathrm{r} \cdot \mathrm{min}^{-1}$. Under the optimal conditions, the average of adsorption rate was $93.15 \%$.The pomelo peel is a promising, cheap, efficient, new biological materials of adsorption for neutral red in wastewater.

\section{Acknowledgments}

This work was supported by National innovation and entrepreneurship training program (No.201611842004) and technology Project of Zhejiang Province, China (No. 2014C31138).

\section{References}

[1] Y.Z. Sun, R.M. Gong, X.P. Zhang, H.J. Liu, C. Yang, China Environmental Science, S1, 2005, pp. 61-64.(In Chinese)

[2] G. Taguchi,System of experimental design:engineering methods to optimize quality and minimize costs. In White Plains:unipub:1987;Vol.1. 
[3] W.H. Zou, K. Li, H.J. Bai, X. Zhao, R.P. Han,Journal of Zhengzhou University (Engineering Science), vol. 6, 2010, pp. 87-90.(In Chinese)

[4] C.X.Ma, K.T.Fang, Erkki Liski. A new approach in constructing orthogonal and nearly orthogonal arrays[J]. Metrika,2000,50(3):255-268.

[5] R.Qian,Biostatistics [M]. Beijing: Higher Education Press, 1999.126- 129. (in Chinese) 